\title{
Distribution and structural characteristics of the Xi'an Section of the Weihe Fault
}

\author{
SHI Ya-qin” (师亚芹) FENG Xi-jie (冯希杰) DAI Wang-qiang (戴王强) REN Jun (任 隽) \\ LI Xiao-ni (李晓妮) HAN Heng-yue (韩恒悦) \\ Earthquake Administration of Shaanxi Province, Xi' an 710068, China
}

\begin{abstract}
The results of seismic deep reflection, high resolution refraction and shallow artificial seismic exploration indicate that the fault on the northern bank of the Weihe river is composed of two faults, one is the Yaodian-Zhangjiawan fault and the other is the Chuanzhang-Zuitou fault. The $22 \mathrm{~km}$ long Yaodian-Zhangjiawan fault of EW-striking starts from Chenjiagou via Yaodian town, Qianpai village, Bili village, Wujia town and Zhangjiawan to Jiajiatan. The $15 \mathrm{~km}$ long Chuanzhang-Zuitou fault striking near EW starts from Chuanzhang via Mabei to Zuitou. The Weihe fault offset the basement and upper crust, the reflecting layers of $T_{\mathrm{Q}}, T_{\mathrm{N}}, T_{\mathrm{E}}$ and $T_{\mathrm{g}}$ are ruptured at depth of about $15 \mathrm{~km}$. In the deep part, the Weihe fault and the secondary fault form a Y-shaped structure or a synthetic low angle intersection. The Weihe fault is a listric normal fault. The fault has obvious structural characteristics of a reversed-drag normal fault and a normal drag normal fault with the depth of $1000 \mathrm{~m}$, and also has the characteristics of syngenetic sediment. The Weihe fault is one of the faults which control the basin sediment, and it is the boundary fault of Xi'an depression and Xianyang salient. The depth of the fault decreases from the west to east gradually, the deep part intersects with the Lintong-Chang'an fault at the intersection part of Weihe River, Jinghe River and Bahe River and the shallow part connects with the Weinan-Jingyang fault. The seismic exploration results indicate that no fault exists on southern bank of the Weihe River.
\end{abstract}

Key words: Weihe fault; seismic deep reflection; high resolution refraction; shallow artificial seismic prospecting; reversed-drag normal fault

CLC number: P315.2 Document code: A

\section{Introduction}

The Weihe river fault (Weihe fault) is an important concealed normal faulting in the Weihe river basin (Weihe basin). There are many different opinions about the distribution of the Weihe fault. According to the landform and physiognomy, YAN (1965) believed that taking Caotan as the boundary of Weihe fault, the Weihe fault dipped to south on the west to it and to north on the east to it; and he also proposed the opinion of 'Quaternary big rotary fault in Weihe vally'. Based on a lot of geological investigations, geophysical explorations and drilling, the Third Petroleum Exploration Brigade of State Geology Administration ${ }^{\Phi}$ (1977) proposed the Baoji-Xianyang-Xingping

\footnotetext{
* Received 2008-01-21; accepted in revised form 2008-08-22.

Foundation item: The Project from State Development and Reform Commission (20041138) and Joint Seismological Science Foundation of China (A07109).

* Author for correspondence: syq0651@sina.com

(1) The Third Petroleum Exploration Brigade of State Geology Administration. 1977. The geological result report in petroleum reconnaissance period of Fen-Wei basin.
} 
fault and pointed out that the fault started in west from Baoji, and extended via Meixian, Wugong, Xingping, Xianyang to Bahe; they thought of that the fault was an basement lithofacies delimitation. The Bureau of Geology and Mineral Resources of Shaanxi Province in 1980 was the first to expand the Weihe fault from Bahe to Tongguan and in 1990 was the first to propose that the Weihe fault is composed by Weihe river northern bank fault (Weihe northen bank fault) and Weihe river southern bank fault (Weihe southern bank fault); the Weihe northern bank fault dips to the south and the Weihe southern bank fault dips to the north; the fault has a certain reflection on the physiognomy ${ }^{\circledR}$ (City Planning Administration of Xi'an, Xi'an Institute of Survey and Mapping, 1998). There are fewer researches (PENG, 1992; FENG et al, 2003a, b; FENG and DAI, 2004) on the structure, nature and activity of the region, lacking deeper and more specific exploration information on the region.

The Weihe fault is one of the faults surveyed under the Project of Xi' an Active Fault Survey and Seismic Risk Assessment. At present, the artificial seismic exploration is usually used to judge whether fault exist or not and accurately determine the location as well as structural characteristics of the fault, and the results are then verified through drilling and prospecting trench. The artificial seismic exploration is now considered as the most effective method to explore buried fault (FANG et al, 2006; XIANG, 2003). SHI et al (2007) carried out seismic deep reflection, the wide angle reflection/refraction, the high resolution refraction joint profile survey, the controlled shallow earthquake and shallow earthquake explorations across the Weihe basin and obtained the distribution and the structural characteristic in the deep, medium-deep and shallow. Meanwhile, the latest activity of the fault was researched.

\section{Regional geologic and geomorphologic background}

The Weihe basin where the Weihe fault located is a tensional fault basin in Cenozoic, it is located on the south-west margin of the North China faulting block according to tectonic structure. The north of the Weihe fault basin is the complete and stable Ordos block; and on the south is the strongly lifting Qinling fault block mountain; the west end connects with the arc fault of south-west margin of the Ordos block; and the east connects with the dextral shear extensional zone of Shanxi.

The Weihe basin was formed in Eocene and developed in Oligocene, the basic outlook of present fault zone was established in Pliocene, and the pattern in the Pliocene is generally inherited in the Quaternary period. The different block movements caused by fault activity is the basic pattern of fault zone evolvement, the significant block subsidence and corresponding thick Cenozoic accumulation is the main behaviors of fault zone evolvement, for example, the Xi' an and Gushi depressions are two subsidence centers within the region.

The Weihe fault zone is located at the intersection of the Xi'an depression and Xianyang salient, two secondary tectonic units of the Weihe basin, and is the boundary fault of the two secondary tectonic units. The Xi'an depression to the south of Weihe fault started to receive sediment in Eocene, the sediment thickness in Cenozoic is more than $7000 \mathrm{~m}$, and the greatest thickness in Quaternary is about $1100 \mathrm{~m}$. The physiognomy develops stream terrace. The ground elevation is $345 \mathrm{~m}$ to $440 \mathrm{~m}$. The Paleogene is absent in the Xianyang tableland in the north of the Weihe fault, the total thickness of lower Pleistocene and Neogene is about $3000 \mathrm{~m}$ and overlaps towards the

\footnotetext{
${ }^{(1)}$ Bureau of Geology and Mineral Resources of Shaanxi Province. 1990. Evaluation and Research of Regional Crustal Stability and Geological Hazards in Xi'an Area.
} 
north. The Earth's surface is middle-late Pleistocene loess, and the thickness is about $100 \mathrm{~m}$. The elevation of the loess tableland changes between $642 \mathrm{~m}$ and $418 \mathrm{~m}$, and inclines to the southeast.

\section{Medium-deep and deep exploration of the Weihe fault}

\subsection{Seismic deep reflection exploration}

The deep seismic reflection exploration profile is from Shachang village of Taiyigong town in Chang'an district to Fuguanzhai of Junma town of Liquan County with length of $69 \mathrm{~km}$ and orienting NW-SE (Figure 1).

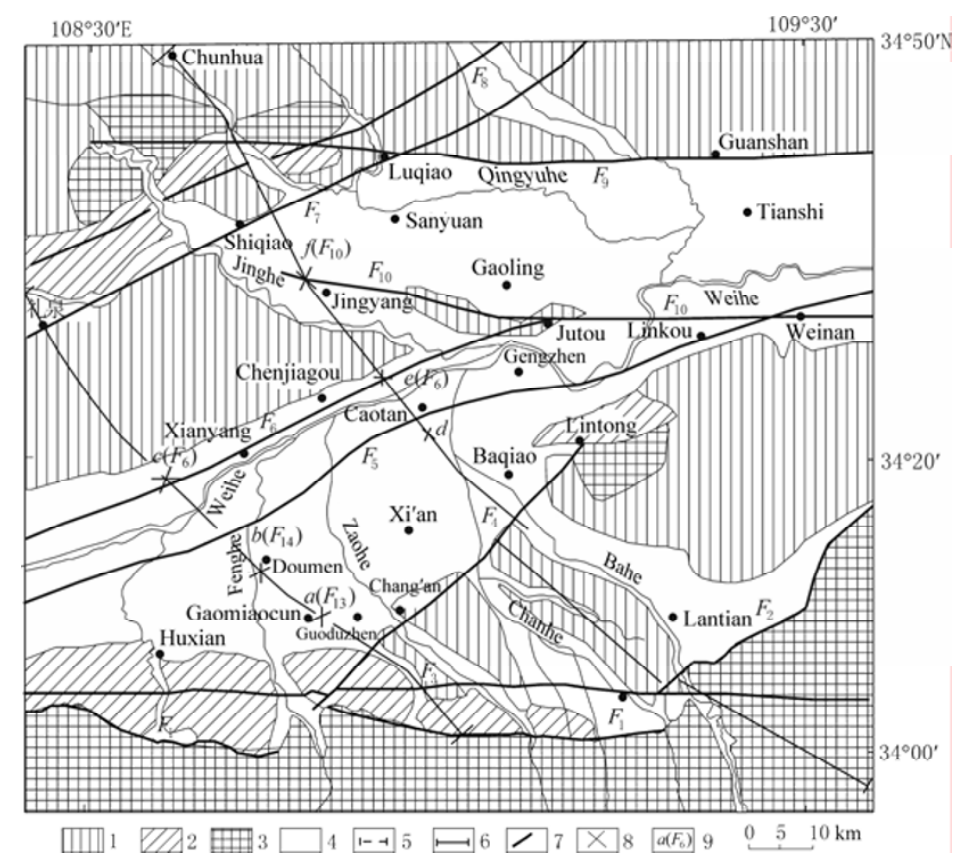

Figure 1 The distribution of the Weihe fault and survey lines

1. Loess tableland; 2. Proluvial fan; 3. Bedrock mountain; 4. River alluvium plain; 5 . Deep reflection survey line; 6 . High resolution refraction survey line; 7. Fault; 8 . Break point obtained in deep earthquake, 9 . The fault numbers in the deep reflection and high resolution refraction profile are shown in bracket; $F_{1}$ : the north edge fault of Qinling; $F_{2}$ : the west-side fault of the Huashan mountain; $F_{3}$ : the Huxian-Tieluzi fault; $F_{4}$ : the Lintong-Chang'an fault; $F_{5}$ : the Weihe southern bank fault; $F_{6}$ : the Weihe northern bank fault; $F_{7}$ : the Fufeng-Sanyuan fault; $F_{8}$ : the Qianxian-Fuping fault; $F_{9}$ : the Kouzhen-Guanshan fault; $F_{10}$ : the Weinan-Jingyang fault

The deep seismic reflection adopts the SUMMIT digital seismograph produced by the DMT Company from Germany, 300 seismic channels are used to receive, among which the effective channels are 240. The sampling rate is $2 \mathrm{~ms}$, the record length is $16 \mathrm{~s}$, and every seismic channel uses one geophone serial which has twelve $10 \mathrm{~Hz}$ geophones. A surveillance system which is chasing excitation with unsymmetrical middle part and covered for several times is adopted, the parameters are as follows. The track interval is $40 \mathrm{~m}$, the minimum offset is $0 \mathrm{~m}$, the maximum offset is $3200 \mathrm{~m}$ and $6400 \mathrm{~m}$, the covering time is 30 to 40 . The generation of seismic wave adopts the drilling blasting hypocenter. After the experiment, the drilling depth is $20 \mathrm{~m}$ to $25 \mathrm{~m}$, the drilling should penetrate the ground water table, and the induced charge of single shot is $24 \mathrm{~kg}$. When the drilling depth can not achieve the design requirements, the excitation mode combined 2 to 3 holes is adopted, and the induced charge of single shot is $18 \mathrm{~kg}$ to $24 \mathrm{~kg}$. 
The profile exploration depth scope of the deep seismic reflection is from the bottom of Quaternary cover to the Moho surface, and thus the deep structural characteristic of the Weihe fault basin can be ascertained as shown in Figure 2. It shows that when the profile double-pass reaches the part shallow than $4 \sim 4.5 \mathrm{~s}$, there are several groups of reflection interfaces of strata with strong energy and good horizontal continuity, the reflection horizon in the north of $50 \mathrm{~km}$ inclines to south; the reflection horizon in the south of $50 \mathrm{~km}$ inclines to the north, and the reflection horizon between $50 \mathrm{~km}$ to $26 \mathrm{~km}$ is elementally level. The reflection horizon has obvious sedimentary basin reflection characteristic, and the basin center is about $35 \mathrm{~km}$. According to the reflection event dislocation, the change of formation interface occurrence and the analysis on the idiovariation of reflected energy, the profile shows several faults. According to the position of each fault on the Earth's surface relative to each fault, $F_{6}$ located at stake about $51 \mathrm{~km}$ is the Weihe north bank fault. The fault ruptured the reflecting layer of $T_{\mathrm{Q}}$ of Quaternary overburden, the Paleogene, the Neogene and the basement reflection $\left(T_{\mathrm{N}}, T_{\mathrm{E}}\right.$ and $T_{\mathrm{g}}$ ); it penetrates $\mathrm{C}$ interface (equal to upper crust) at a low angle in the depth about $13 \mathrm{~km}$, and it stops at the depth of $2 \mathrm{~km}$ under the $\mathrm{C}$ interface. At the depth of $\mathrm{C}$ interface, the inclination angle of Weihe fault has become gently, at this point, the main form of rupture of the Weihe fault to the crust $\mathrm{C}$ interface is the nearly horizontal stretching (FENG et al, 2008). The fault is the shovel-shaped normal fault, the inclination angle of shallow fault is steep, and the inclination angle becomes gently with the increasing of depth.

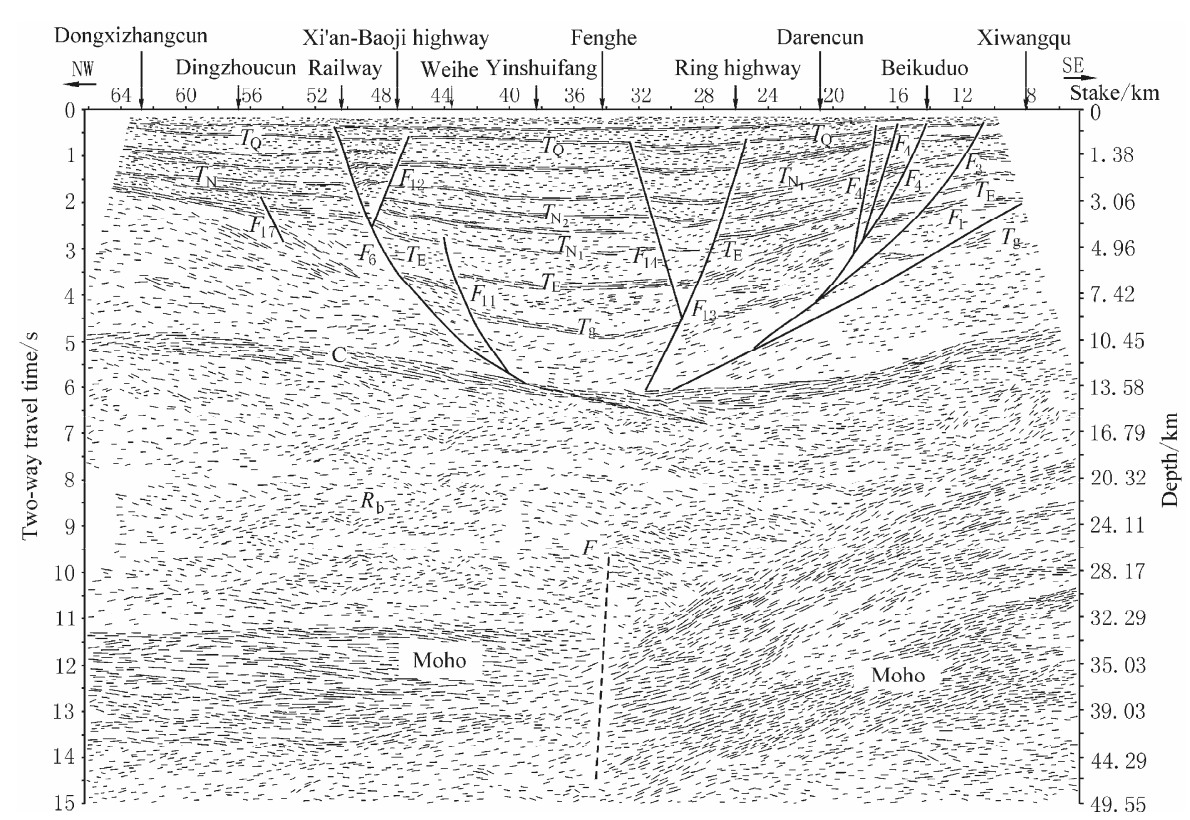

Figure 2 The deep seismic reflection profile ${ }^{\mathbb{1}}$

$T_{\mathrm{Q}}$ : the quaternary system floor reflected wave group; $T_{\mathrm{N}_{2}}$ : the Pliocene floor reflected wave group; $T_{\mathrm{N}_{1}}$ : the Miocene floor reflected wave group; $T_{\mathrm{E}}$ : the Paleogene floor reflected wave group; $T_{\mathrm{g}}$ : the crystalline basement reflected wave group; $F_{1}$ : the north edge fault of the Qinling mountain; $F_{3}$ : the Huxian-Tieluzi fault; $F_{6}$ : the Weihe northern bank fault; $F_{11}$ and $F_{12}$ : the branch fault of Weihe fault; $F_{13}$ and $F_{14}$ and $F_{17}$ : the newly-found faults; $F$ : the Moho surface deep fault; $\mathrm{C}$ : the strong reflected wave group, which equals to the reflected wave group of the middle part of crust in $R_{\mathrm{A}}$ and $R_{\mathrm{B}}$ of upper crust floor ${ }^{\circledR}$; Moho: the Moho surface

\footnotetext{
${ }^{(1)}$ The Center of Geophysical Exploration, China Earthquake Administration 2005. Deep Seismic Detecting Report of the Project of Xi'an Active Fault Survey and Seismic Risk Assessment.
} 
When the double-pass reaches $2.2 \mathrm{~s}$, the time-depth of sedimentary reflection in the north of Weihe fault is maximal, the sedimentary strata has Neogene and Quaternary system, and the Paleogene is absent; the reflection horizon in the south of fault is increased, when the double-pass reaches $4.5 \mathrm{~s}$, the sedimentary strata has Paleogene, Neogene and Quaternary system, the Neogene is obviously thicker than the north side of fault, it means that the Weihe fault has an obvious control to the sediment of Paleogene and Neogene in the basin. The south side of fault sinks to receive the great Paleogene and Neogene accumulation; the north side of fault continues to uplift, the Paleogene accumulation is absent and the Neogene accumulation is correspondingly thin. The difference between the crystalline basements on two sides is $4 \mathrm{~km}$. The south of Weihe fault is Xi'an depression, the north is Xianyang salient, and the Weihe fault is the boundary fault of Xi'an depression and Xianyang salient. $F_{11}$ and $F_{12}$ should be the secondary fault of $F_{6}, F_{11}$ only ruptured $T_{\mathrm{E}}$ and $T_{\mathrm{g}} ; F_{11}$ mergers on $F_{6}$ at the depth of $10 \mathrm{~km}$ and intersects with $F_{6}$ at low angle. $F_{12}$ only ruptured $T_{\mathrm{N}_{1}}$ and $T_{\mathrm{Q}} ; F_{12}$ mergers on $F_{6}$ at the depth of $3.2 \mathrm{~km}$ to $3.5 \mathrm{~km}$, the tendency of $F_{12}$ is reversed with that of $F_{6}$, and a Y-shaped structure is formed. The position of $F_{12}$ fault extended to the Earth's surface locates at the northern bank of Weihe.

$F_{13}$ and $F_{14}$ in the profile are two new faults detected in the deep reflection. The positions of the faults are about stakes of $25.5 \mathrm{~km}$ and $33 \mathrm{~km}$ and the planimetric positions are near the Doumen and Gaomiao village of Guodu (Figure 1). Two faults are antithetic inclined; both of them ruptured the bottom interface of Quaternary overburden with different downward elongated depth; fault $F_{13}$ ruptured reflecting interfaces $T_{\mathrm{Q}}, T_{\mathrm{N}}, T_{\mathrm{E}}$ and $T_{\mathrm{g}}$ and elongates downward about $13.6 \mathrm{~km}$ to $\mathrm{C}$ interface, and fault $F_{14}$ elongates to the depth of $8.5 \mathrm{~km}$ to $9 \mathrm{~km}$ and stops above the fault $F_{13}$. At present, many people believe that Weihe southern bank fault locates at the advancing edge of first terrace on the southern bank of the Weihe river, the position of it is about $42 \mathrm{~km}$ on the deep reflection profile, the stratum interface in this location is stable, and no obvious image of fault is reflected in co-phase axis. There is no indication of fault on the southern bank of the Weihe river.

\subsection{High resolution refraction exploration}

The high resolution refraction survey line locates at the northeast side of Xi' an city, between Lantian and Chunhua counties (Figure 1), and it coincides with the seismic wide-angle reflection/refraction at the same direction. The dot pitch of high resolution seismic refraction survey is $0.5 \mathrm{~km}$ to $0.8 \mathrm{~km}$, the number of shot points are 9 (wherein seismic wide-angle reflection/refraction profile share 2 shot points); the average shot distance is $12 \mathrm{~km}$, and a complete multiple system of observations by correlative meeting and pursuing. The data of the high resolution seismic refraction profile from $150 \mathrm{~km}$ to $400 \mathrm{~km}$ on the survey line from Danfeng county in the southeast of Xi'an to Binxian county in the northwest of Xi'an is processed and interpreted. The high resolution seismic refraction profile crosses the main fault zone of the Weihe basin. The generation of seismic wave adopts the downhole combination explosive blasting mode. In the soil sedimentary area, the depth of wells is required to exceed the ground water table and not less than $25 \mathrm{~m}$; if the water level is deep, the depth of wells is not less than $30 \mathrm{~m}$. In the gravel layer area, a combination of shallow wells and multi-wells are adopted, the depth of the wells is $7.1 \mathrm{~m}$ to 52.0 $\mathrm{m}$, and the explosive quantity is different from $600 \mathrm{~kg}$ to $1400 \mathrm{~kg}$.

Pg wave is the reflected wave of basement top, the initial motion is clear, the phase identification is almost not needed to be carried out, and the reliability is the highest. The 2-D velocity structure and structural interpretation diagram (Figure 3) of stegine and basement are gained 
through the finite-difference inversion of Pg wave. From the diagram we can see that the Xi'an depression has two faults, $F_{6}$ which is about stake of $296 \mathrm{~km}$ is the Weihe northern bank fault and inclines to southeast, the depth is about $6 \mathrm{~km}$ and is less than the fault depth in the deep reflection profile. $F_{4}$ which is about stake of $277 \mathrm{~km}$ is the Lintong-Chang' an fault and inclines to northwest, and the depth is about $6 \mathrm{~km}$. The Weihe northern bank fault intersects with the Lintong-Chang'an fault in deep depths. The $F_{13}$ and $F_{14}$ fault which are newly found in deep reflection profile seems to have reactions at the $285 \mathrm{~km}$, stake of the high resolution profile, but the display is not obvious. The Weihe southern bank fault should be about stake of $290 \mathrm{~km}$, but the fault is not obviously displayed in this position.

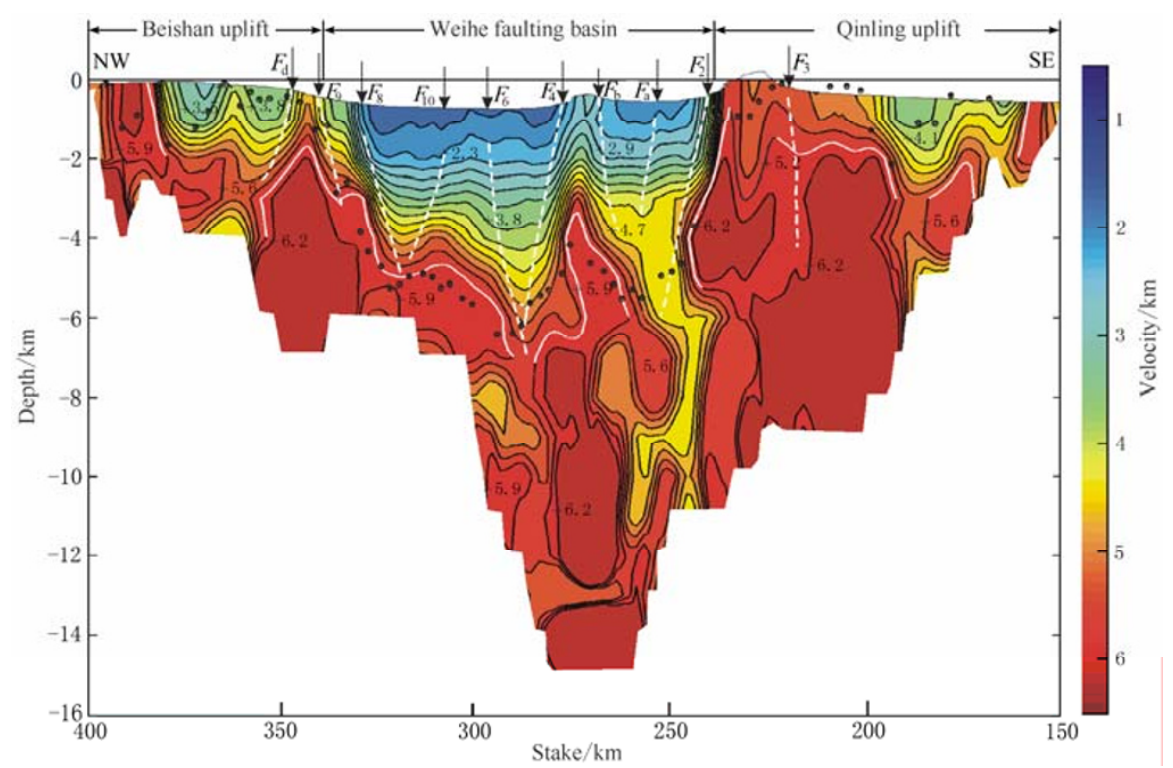

Figure 3 The high resolution seismic refraction profile ${ }^{(1)}$

$F_{2}$ : The Huashan west side fault; $F_{3}$ : The Tieluzi fault; $F_{4}$ : The Lintong-Chang'an fault; $F_{6}$ : The Weihe northern bank fault; $F_{8}$ : The Qianxian-Fuping fault; $F_{9}$ : The Kouzhen-Guanshan fault; $F_{10}$ : The Weinan-Jingyang fault; $F_{\mathrm{a}}, F_{\mathrm{b}}$ and $F_{\mathrm{d}}$ are the new-found fault; the white dashed line in the figure is the fault, the white solid line is basement topsuperface, and the black cycle is the basement topsuperface gained by the inversion of time term

\section{Shallow seismic exploration}

The shallow seismic explorations are divided into two steps. The controlling shallow seismic exploration is carried out firstly, and the shallow seismic detailed exploration is carried out later. The exact positioning scope of Weihe fault starts from the Chenjiagou in the east of Xianyang, and moves eastward through the intersection part of the Weihe river, Bahe river and the Jinhe river to Zuitou, and the length is about $40 \mathrm{~km}$.

\subsection{Controlling shallow seismic exploration}

Based on sufficient collected information and field investigation, two controlling shallow artificial seismic survey lines were set across the Weihe fault. The first survey line was located along the Xibailiang of Sanqiao town of Xi'an city and Chenjiagou of Yaodian town of Xianyang city,

\footnotetext{
(1) The Research Center of Exploration Geophysics of China Seismological Bureau. 2005. Deep Seismic Detecting Report in the Project of Xi'an Active Fault Survey and Seismic Risk Assessment.
} 
the length of the north survey line $X A_{2-1}$ is $8280 \mathrm{~m}$, and the south survey line $X A_{2-2}$ is $4560 \mathrm{~m}^{\mathbb{1}}$. The second survey line extended along Laoaotan in the northern suburbs of Xi'an and Weihe Power Plant of Xianyang, the length of the north survey line $L_{2}$ is $8010 \mathrm{~m}$ long, and the south survey line $L_{3}$ is $6040 \mathrm{~m}$ (Figure 4). The survey line crosses over the Weihe northern bank and southern bank fault. The target horizon of the exploration is the Quaternary system bottom, and the depth is about $1200 \mathrm{~m}$.

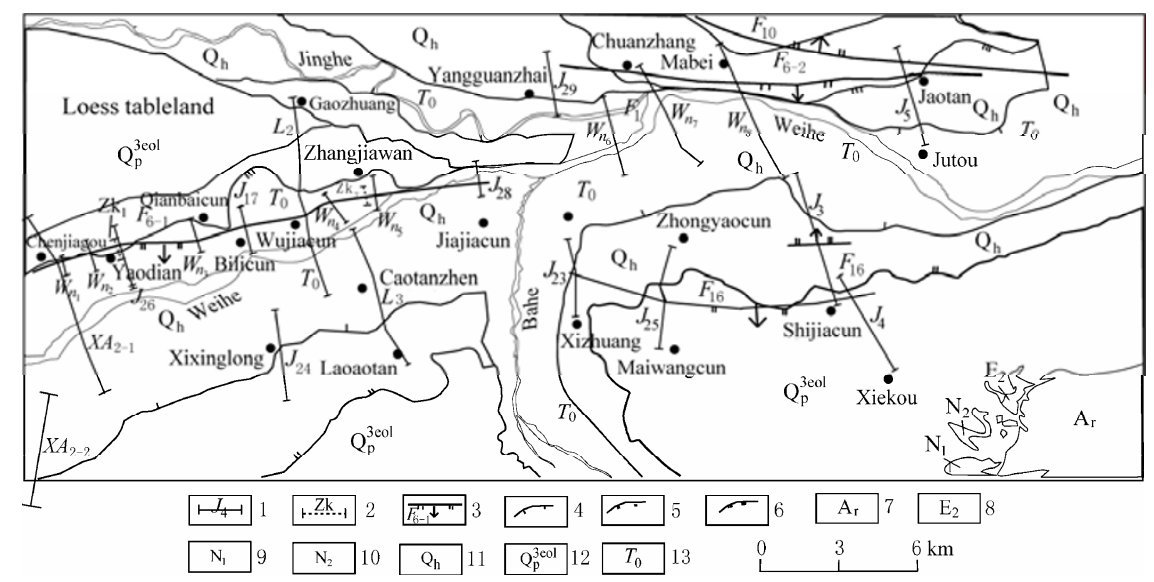

Figure 4 Distribution of survey lines for the Weihe fault shallow seismic exploration

1. Shallow seismic survey line and its number; 2. Drilling profile and its number; 3 . Normal fault and its number; 4 . The first terrace; 5 . The second terrace; 6 . The third terrace; 7. Archean; 8 . Eocene series; 9. Miocene; 10. Pliocene; 11. The Holocene alluvium: 12. The late Pleistocene wind deposition; 13. floodplain; $F_{6-1}:$ The Yaodian-Zhangjiawan fault; $F_{6-2}$ : The Chuanzhang-Zuitou fault; $F_{16}$ : The Xinzhu-Jiacun fault; $F_{10}$ : The Weinan-Jingyang fault

The test of the well depth, generation quantity and expanded spread experiment were carried out before the exploration. The main geomorphic units of measuring zone are the terrace covered by loess, the low terrace and floodplain not covered by loess. In the two geomorphic units, there have different well depths, different generation quantities and receiving spreads as well as different observational parameters.

The controlling shallow seismic survey lines are $X A_{2-1}$ and $X A_{2-2}$, the track pitch is $10 \mathrm{~m}$; the shot interval is $30 \mathrm{~m}$; the offset distance is $80 \mathrm{~m}$ to $100 \mathrm{~m}$; the stacking fold is 12 times; the 72 traces receiving; single-ended spread. The sampling length is $0.5 \mathrm{~ms}$; the record length is $2 \mathrm{~s}$. High resolution SUMMIT wired telemetry digital seismograph is adopted. The control shallow seismic survey line $L_{2}$, the track pitch is $5 \mathrm{~m}$; the shot interval is $18 \mathrm{~m}$ to $20 \mathrm{~m}$; the offset distance is $80 \mathrm{~m}$ to $100 \mathrm{~m}$; the stacking fold is 12 times; the 96 traces receiving; single-ended single point shooting mode; the spread length is $475 \mathrm{~m}$; the sample length is $1.0 \mathrm{~ms}$; the record length is $2 \mathrm{~s}$. The DS-6 type 300 traces telemetry digital seismograph produced in American is adopted.

The explosive source generated in well is adopted, the hole is formed with artificial mobile drill. The depth of generation well is about $14 \mathrm{~m}$, and the depth of the well in loess tableland area is greater than $20 \mathrm{~m}$. It is most desirable that the depth of the generation hole reaches or is close to the underground water table. The generation quantity is about $2 \mathrm{~kg}$ to $4 \mathrm{~kg}$. If the hole depth can

\footnotetext{
${ }^{(1)}$ Institute of Geophysical and Geochemical Exploration, Chinese Academy of Geological Sciences, State Research Center of Modern Geological Exploration Engineering Technology 2005. Shallow Artificial Seismic Control Exploration Report in the Project of Xi'an Active Fault Survey and Seismic Risk Assessment.
} 
not achieve the requirements because of calcareous concretion or gravel layer, the method of shallow hole combination generation is adopted. The measured result can be seen in Figure 5. The signal to noise ratio of the profile is high, and the characteristic of the wave group is obvious.

Four seismic reflected wave groups are identified from the time-depth profile of $L_{2}$ survey line in Figure 5. The wave groups reflect that the strata overall inclines to the south. Judging according to the change of wave group occurrence, a fault exists near CDP3167. The difference between the two fault walls reflects the marker horizon occurrence is great; the footwall occurrence is level; the hanging wall is close to the fault and pulled and bended downward; the hanging wall declines; the footwall ascends; the fault inclines to the south; the virtual inclination is $85^{\circ}$, and the inclination angle increases quickly with the increasing of the depth; the fault is the obvious reversed-drag high angle normal fault, and the quaternary system floor fault throw of the fault is $100 \mathrm{~m}$. On the physiognomy, the fault locates at high floodplain, and it is $1000 \mathrm{~m}$ to the advancing edge of the third stage terrace. The survey line $X A_{2-1}$ seismic profile also has clear fault display, and the fault locates at the toe of slope zone at the advancing edge of the third stage terrace.

The seismic time-depth profiles are divided into five reflected wave groups on survey line $L_{3}$ in Figure 5. The reflected wave groups reflect that the north part of strata inclines to the south; the south part of strata inclines to the north; the virtual inclination of strata on the two wings is $4^{\circ}$ to $6^{\circ}$; the wave group is concentrated and the continuity is stable; the strata is a nearly symmetrical relieved syncline. No faults are seen on this survey line. The co-phase axis of seismic time profile of survey line $X A_{2-2}$ on the southern bank of the Weihe river is stable and continuous, without image of fault.
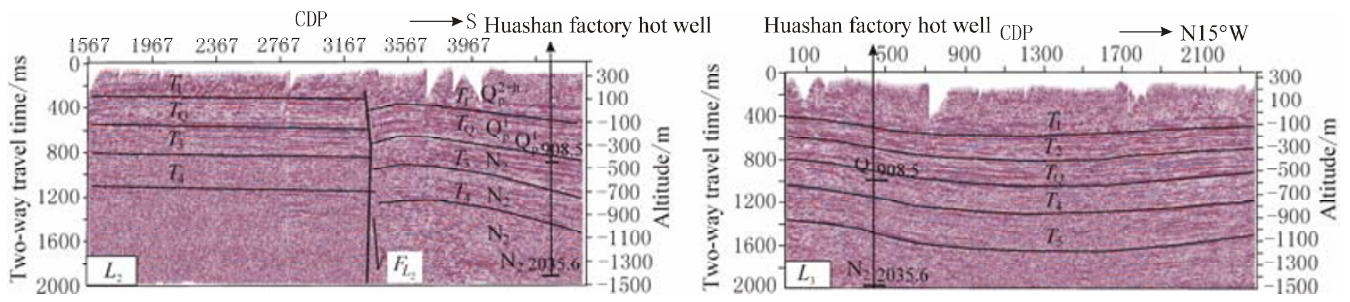

Figure 5 The time-depth diagram of seismic reflection profiles of survey lines $L_{2}$ and $L_{3}{ }^{(1)}$

$T_{1}$ : The strong reflection interface; $T_{\mathrm{Q}}$ : The Quaternary system floor reflected wave group; $Q_{\mathrm{p}}^{2+\mathrm{h}}$ : The mid Pleistocene series to Holocene; $Q_{\mathrm{p}}^{2}$ : The mid Pleistocene series; $Q_{\mathrm{p}}^{1}$ : The lower Pleistocene series; $\mathrm{N}_{2}$ : The Pliocene; Q Q Qtaxs : The drilling hole, the left side is strata, the data on the right side is the depth of the strata on the left side; $F_{12}$ : The fault and number; $L_{2}$ : The seismic survey line number

\subsection{Shallow seismic detailed exploration}

The target horizon depth of shallow seismic detailed exploration is $200 \mathrm{~m}$ to $600 \mathrm{~m}$; the actual exploration depth is about $1000 \mathrm{~m}$. 18 survey lines are embedded, the density of the survey line is obviously increased, and the interval between two neighboring survey lines is not greater than $2.5 \mathrm{~km}$ (Figure 4). Through the field assay experiment, different collections and observing systems are used for the terrace, alluvial high and low floodplain covered by loess. (1) For the survey line located at the alluvial low terrace or floodplain, the best depth of generation hole should reach or be close to the underground water table, and the drilling depth should be increased if the underground water table of loess tableland zone is deep. (2) The explosive used for the shock is the packaged am-

\footnotetext{
${ }^{11}$ China Coal Research Institute Xi'an Branch. 2005. Shallow Artificial Seismic Control Exploration Report in the Project of Xi'an Active Fault Survey and Seismic Risk Assessment.
} 
monium-antimony explosive with high density and good sealing specially used for the seismic exploration, the quantity is $1.0 \mathrm{~kg}$ to $1.5 \mathrm{~kg}$, the sample rate is $1 \mathrm{~ms}$, and the record length is $0.8 \mathrm{~s}$ to 1.2 s. (3) When the underground water table of the alluvial-proluvial plain and fluvial plain is shallow, the split shooting and unequally spaced receiving observing system can be used, the total receiving traces of the device are 192; the reasonable way is that the unequally spaced minor edge has 72 traces, and the long edge has 120 traces. (4) When the depth of the ground water is deep and the loess horizon is thick, the surface wave interference of seismic split shooting and unequally-spaced receiving is great, the loss of the deep part information is serious; the seismic exploration can use the single side shooting and 144 traces receiving, but the principle that the offset distance must be as small as possible must be maintained. The offset distance normally is about $18 \mathrm{~m}$, but should be adjusted to about $36 \mathrm{~m}$ if the loess horizon is thick and the ground water is deep, and the surface wave interference can be decreased. (5) The deep part should also be combined with the shallow artificial seismic exploration of the active fault in Xi'an, considering the relationship of spread and the best exploration depth and combining the factors of the used apparatus, the track pitch is $3 \mathrm{~m}$, the shot interval is $10 \mathrm{~m}$ to $18 \mathrm{~m}$, and the covering numbers are 12 to 16 times. (6) The DS-6 type 300 traces telemetry digital seismograph produced in American is used. The measuring result can be seen in the Figures $6 \sim 9^{\mathbb{1}}$.

From the diagrams, the profile signal-to-noise ratio is high, the characteristics of the wave group are clear, and the event continuity is good. There are 3 or 4 reflected wave marker horizons in the profile. The fault is judged to exist or not according to if the reflected wave group event is leaped or not, if the event number is obviously increased or disappeared, and if the thickness of the same reflected wave group changes or not. 15 survey lines in 18 shallow seismic survey lines used for the detailed exploration show fault display. The main manifestations are as follows.

1) The normal fault of reversed-drag structure. The profiles which have the fault characteristic are $J_{17}, W_{n_{4}}, W_{n_{7}}, J_{23}, J_{3}, W_{n_{1}}$ and $W_{n_{5}}$ (Figure 6). The common feature is that the fault hanging wall strata traction bends downward, and the footwall strata is level. The difference of reversed-drag of the fault in each profile is great, the reversed-drag in the first 5 profiles is obvious, and the reversed-drag in the back 2 profiles is not obvious. $J_{3}$ profile is the most classic one; the $J_{3}$ survey line seismic time-depth profile diagram in Figure 6 totally interprets 4 reflected wave groups. According to the change of occurrence of the wave group, three faults $F_{J_{3-1}}, F_{J_{3-2}}$ and $F_{J_{3-3}}$ are respectively on the stake numbers 1700,1225 and 1060. Wherein, the $F_{J_{3-1}}$ fault is on the south end of the survey line, the fault inclines to south; the virtual inclination is $85^{\circ}$; the hanging wall strata inclines to south slightly; the continuity of the wave group is worse; the footwall strata is level; the continuity of the wave group is good, and the occurrence of two foot strata is not harmonious. Wave group correlation strata hanging wall declines, indicating it is the normal fault. The $F_{J_{3-2}}$ fault is on the middle part of the profile, the fault inclines to north, and the virtual inclination is $71^{\circ}$; the hanging strata is bended like an arch, the bending degree is weak in the shallow part, and it strengths gradually with the increasing of the depth, the occurrence of foot wall strata is level, it is an classic reversed-drag structure. The $F_{J_{3-3}}$ fault is near and parallel to the $F_{J_{3-2}}$ fault, it is the concomitance secondary small fault in the forming process of $F_{J_{3-2}}$ fault. The reflected wave occurrence change in the $J_{17}$ survey line seismic reflection time-depth profile displays the

${ }^{11}$ China Coal Research Institute Xi'an Branch. 2007. Shallow Artificial Seismic Detail Exploration Report in the Project of Xi'an Active Fault Survey and Seismic Risk Assessment. 
fault clearly (on CDP4960), the characteristics are prominent. The footwall stratum of the fault is gently and tends to level, the hanging wall is a little inclined, and the strata near the fault bends downward. The fault inclines to the south, the virtual inclination is about $53^{\circ}$, and it is the reversed-drag normal fault declined by southern wall. The fault throw of the fault is $45 \mathrm{~m}$, and the embedded depth of upper fault point is less than $40 \mathrm{~m}$. The fault in the seismic profile $W_{n_{1}}$ and $W_{n_{5}}$ also has the characteristics of reversed-drag structure, but manifestation is not obvious; the hanging wall strata near the fault surface inclines to the foot wall strata slightly, and the fault in $W_{n_{1}}$ and $W_{n_{5}}$ has been validated by the drilling institute ${ }^{\mathbb{D}}$. The fault with unobvious manifestation is easy to be ignored.

2) The positive drag structure of the normal fault. $W_{n_{3}}, J_{28}, J_{25}, J_{4}, J_{5}$ and $W_{n_{8}}$ (Figure 7) seismic time-depth profiles have obvious manifestation. The common feature is that the hanging wall strata near the fault are pulled upward, the foot wall strata is nearly level. The $W_{n_{3}}$ seismic time-depth profile in Figure 7 shows the fault is near CDP2743, the fault inclines to the south. The hanging wall strata near the fault are pulled upward, and the drag phenomenon in the deep part strata is more obvious than that in the shallow part strata. In the $J_{5}$ seismic time-depth profile in Figure 7, there are faults near CDP2070 and 1440, wherein, the scale of $F_{J_{5-1}}$ is the largest, the fault inclines to the south; the inclination angle is approximate vertical; the hanging wall strata near the fault are pulled upward and bended, the inclination angle becomes steep; the inclination angle of the foot wall strata of the fault is near level. $F_{J_{5-2}}$ fault inclines to the north, the cross-fault strata occurrence is near level, but the continuity of foot wall event is relatively bad. The cross-fault reflected wave group is not continuous, and the $F_{J_{5-2}}$ is analyzed to be part of the Weinan-Jingyang fault from the district.

3) The fault shows the characteristic of syndepositional structure. The fault $W_{n_{4}}, W_{n_{1}}, J_{3}, W_{n_{3}}$, $J_{25}$ and $J_{26}$ seismic profiles not only shows the characteristic of traction structure, but also has the characteristic of syndepositional structure. The main manifestation of syndeposition of the fault is that the thickness of the strata hanging wall in the same era on two sides of the fault is thicker than that of the foot wall. The manifestation of $J_{26}$ profile is obvious, and the profile totally interprets 5 seismic reflected wave groups (Figure 8). According to the information of the Weishuiyuan hot well, the profile ${ }^{(2)}$ and relative information of late Quaternary period strata of the Weihe basin (XUE, 2002), in the Weihe river high floodplain zone near the survey line, the depth of Quaternary system floor is about $900 \mathrm{~m}$, the depth of upper Pleistocene series is $20 \mathrm{~m}$ to $30 \mathrm{~m}$, and the depth of Holocene is about $10 \mathrm{~m}$. From the Figure 8, the $F_{J_{26}}$ fault exists in the survey line CDP5160, the fault inclines to south; the virtual inclination is about $64^{\circ}$. The footwall strata is near level, the hanging wall strata is in an obvious radiation-shape; the strata inclination angle is gently in the shallow part, and it becomes steep in the deep part, and the phenomenon that the sedimentary layer of hanging wall strata is thickened when the hanging wall strata kept away from the fault is obvious. From the Table 1 and the Figure 8, the thickness on the south end of the same strata on two ends of the profile is obviously thicker than that on the north end; for instance, the strata between $T_{2}$ and $T_{3}$ reflecting interfaces, the thickness of the south end is $260 \mathrm{~m}$, and the thickness of

\footnotetext{
${ }^{(1)}$ The Survey and Research institute of engineering seismic of Shaanxi Province. 2007. Drilling Geology Report in Project of Xi'an Active Fault Survey and Seismic Risk Assessment.

${ }^{(2)}$ Institute of Geology, China Earthquake Administration. 2007. The Constructing of Quaternary Period Strata Profile of Weihe Basin and Xi'an Active Fault Survey and Seismic Risk Assessment.
} 
the north end is $95 \mathrm{~m}$. The hanging wall strata near the fault plane in the same strata is thicker than footwall strata, the difference of the thickness is $10 \mathrm{~m}$ to $15 \mathrm{~m}$. The reflected wave groups in other profiles show that the difference of the thicknesses of strata which are in the same era on the two
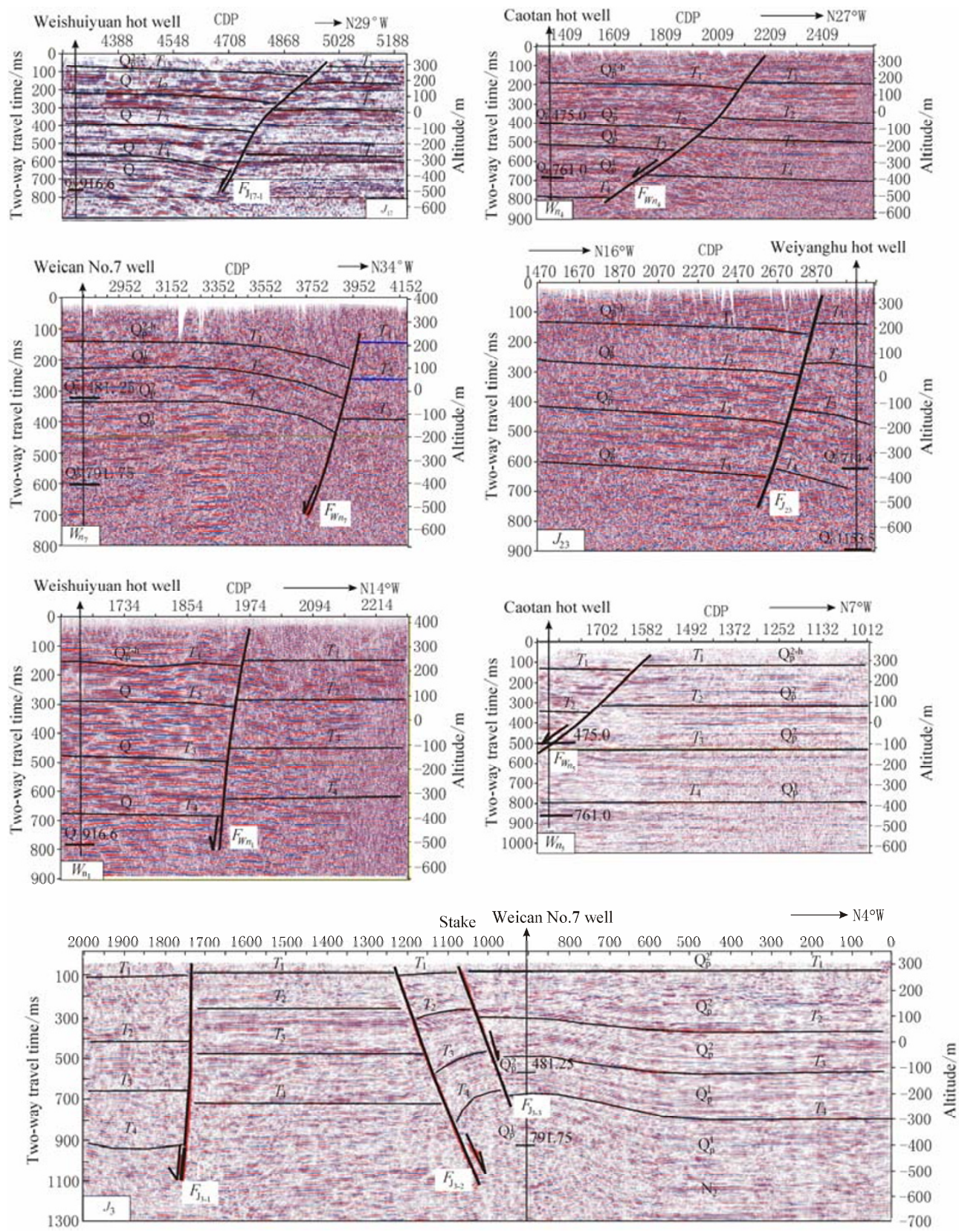

Figure 6 The time-depth diagram of seismic reflection profiles with the characteristic of reversed-drag structure

$T_{1}$ : The strong reflecting interface; $T_{\mathrm{Q}}$ : The Quaternary system; $\mathrm{Q}_{\mathrm{p}}^{2+\mathrm{h}}$ : The mid Pleistocene series to the Holocene; $\mathrm{Q}_{\mathrm{p}}^{2}$ : The mid Pleistocene series; $\mathrm{Q}_{\mathrm{p}}^{1}$ : The lower Pleistocene series; $\mathrm{N}_{2}$ : The Pliocene; $\mathrm{Q}_{\mathrm{p} \text { tol.1.5: }}^{1}$ The drilling hole, the left side is strata, the data on the right side is the depth of the strata on the left side; $J_{3}$ : The seismic survey line number; $F_{J_{23}}$ : The fault and number; $W_{n_{4}}, W_{n_{7}}, J_{23}$ and $W_{n_{1}}$ are the local profiles. 

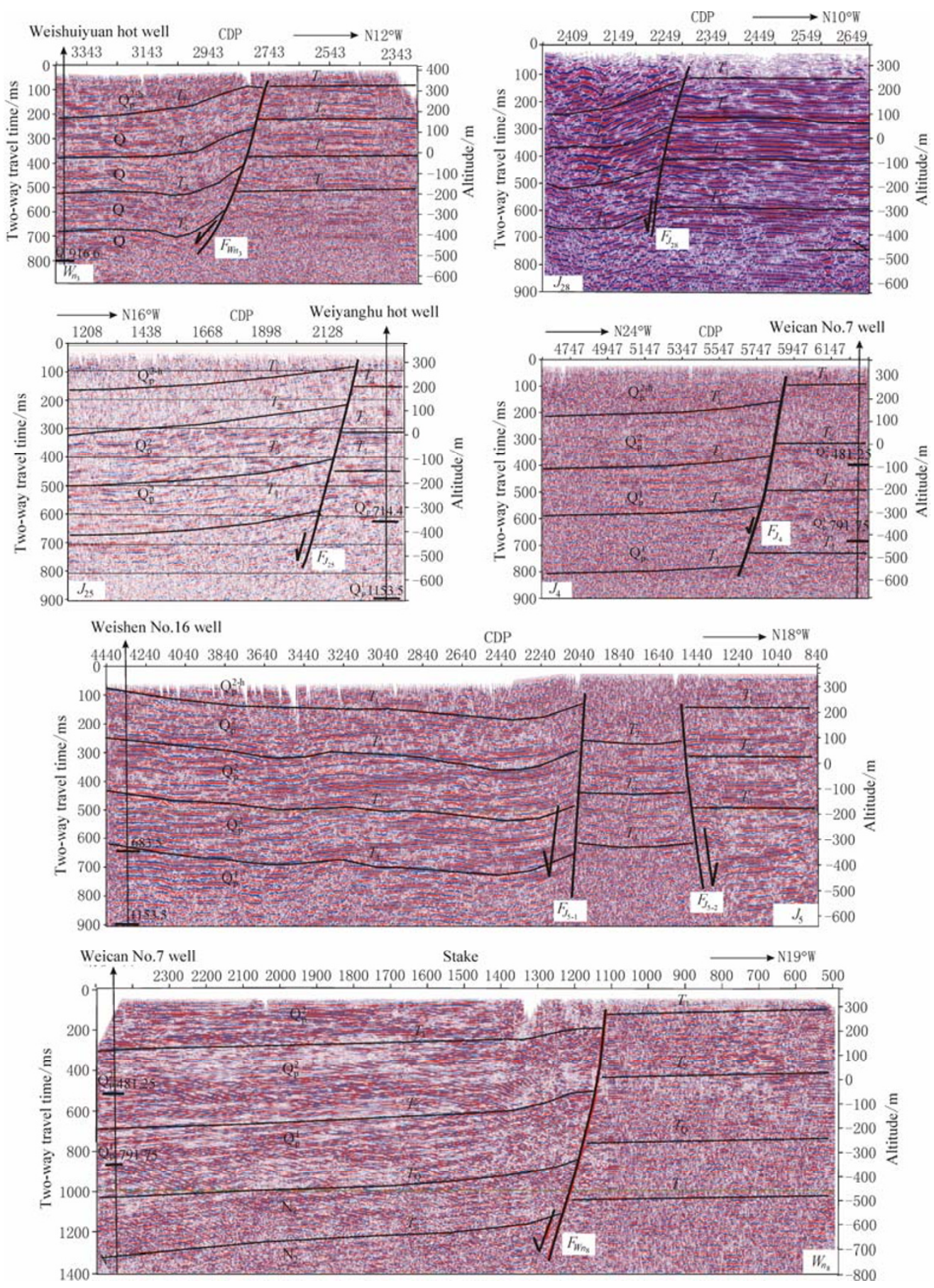

Figure 7 The time-depth diagram of seismic reflection profiles with the characteristic of normal drag structure

$T_{1}$ : The strong reflecting interface; $T_{\mathrm{Q}}$ : The Quaternary system floor reflected wave group; $\mathrm{Q}_{\mathrm{p}}^{2+\mathrm{h}}$ : The mid Pleistocene series to the Holocene; $Q_{p}^{2}$ : The mid Pleistocene series; $Q_{p}^{1}$ : The lower Pleistocene series; $\mathrm{N}_{2}$ : The Pliocene; Q A pons: The drilling hole, the left side is strata, the data on the right side is the depth of the strata on the left side; $W_{n_{3}}:$ The seismic survey line number; $F_{J_{5}}:$ The fault and number; $W_{\mathrm{n}_{3}}, W_{29}, J_{25}$ and $W_{n_{4}}$ are the local profiles 
sides near the fault plane is greater (Table 1), the difference is $20 \mathrm{~m}$ to $40 \mathrm{~m}$, and the maximum difference of the thickness is $100 \mathrm{~m}$, for example, the thickness of $T_{4}$ reflecting interface and the $T_{3}$ reflecting interface which are in the $W_{n_{4}}$ seismic profile on two sides of fault is $350 \mathrm{~m}$ and $250 \mathrm{~m}$, and the difference of the thicknesses is $100 \mathrm{~m}$. The thickness of $T_{4}$ reflecting interface and the $T_{3}$ reflecting interface which are in the $W_{n_{3}}$ seismic profile on two sides of fault is $248 \mathrm{~m}$ and $142 \mathrm{~m}$, and the difference of the thicknesses is $106 \mathrm{~m}$. The above profiles reflect that the fault from the Quaternary period has the characteristic of syndepositional activity.

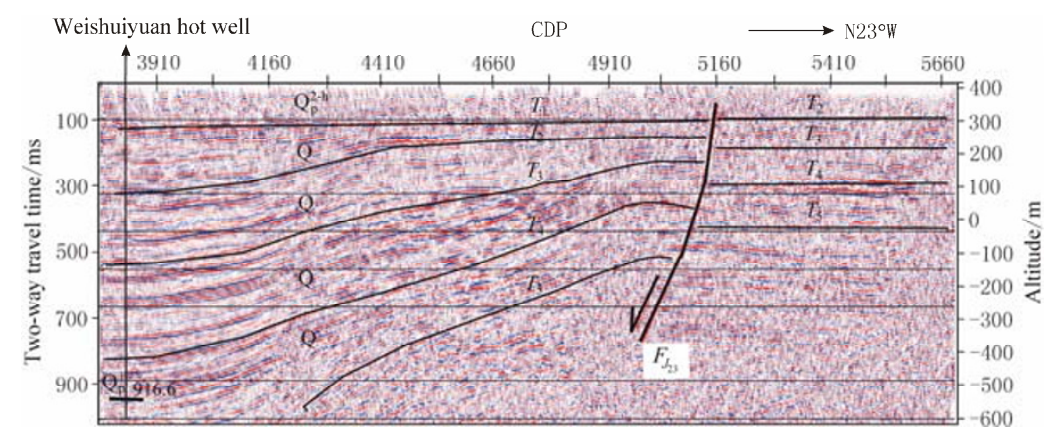

Figure 8 The time-depth diagram of seismic reflection survey line $J_{26}$ $T_{1}$ : The strong reflecting interface; $\mathrm{Q}$ : The Quaternary system; $\mathrm{Q}_{\mathrm{p}}^{2+\mathrm{h}}$ : The mid Pleistocene series to the Holocene; $\mathrm{Q}_{\mathrm{p}}^{1}$ : The mid Pleistocene series; $\mathrm{Q}_{\text {p }}^{1}$ ths: The drilling hole, the left side is strata, the data on the right side is the depth of the strata on the left side; $F_{J_{26}}$ : The fault and its number

Table 1 The correlation table of the thickness of the strata on two sides of syndepositional fault

\begin{tabular}{|c|c|c|c|c|c|c|}
\hline $\begin{array}{l}\text { Survey line } \\
\text { and fault } \\
\text { number }\end{array}$ & $\begin{array}{l}\text { Marker horizon (the } \\
\text { difference of two } \\
\text { neighboring reflect- } \\
\text { ing interfaces) }\end{array}$ & $\begin{array}{c}\text { Strata } \\
\text { age }\end{array}$ & $\begin{array}{l}\text { The strata thick- } \\
\text { ness on the south } \\
\text { end of survey } \\
\text { line } / \mathrm{m}\end{array}$ & $\begin{array}{l}\text { The strata thick- } \\
\text { ness on the north } \\
\text { end of survey } \\
\text { line } / \mathrm{m}\end{array}$ & $\begin{array}{l}\text { The thickness of } \\
\text { the hanging wall } \\
\text { near the fault } \\
\text { interface } / \mathrm{m}\end{array}$ & $\begin{array}{l}\text { The thickness of } \\
\text { the foot wall near } \\
\text { the fault inter- } \\
\text { face } / \mathrm{m}\end{array}$ \\
\hline $\begin{array}{c}J_{26} \\
F_{J_{26}}\end{array}$ & $\begin{array}{c}T_{2}-T_{1} \\
T_{3}-T_{2} \\
T_{4}-T_{3} \\
T_{5}-T_{4}\end{array}$ & $\begin{array}{l}\mathrm{Q}_{\mathrm{p}}^{2-4} \\
\mathrm{Q} \\
\mathrm{Q} \\
\mathrm{Q}\end{array}$ & $\begin{array}{c}140 \\
260 \\
240 \\
>135\end{array}$ & $\begin{array}{c}<100 \\
95 \\
110 \\
135\end{array}$ & $\begin{array}{c}70 \\
95 \\
120 \\
130\end{array}$ & $\begin{array}{c}80 \\
110 \\
120\end{array}$ \\
\hline $\begin{array}{l}W_{n_{4}} \\
F_{W_{\mathrm{n}_{4}}}\end{array}$ & $\begin{array}{l}T_{2}-T_{1} \\
T_{3}-T_{2} \\
T_{4}-T_{3}\end{array}$ & $\begin{array}{l}\mathrm{Q}_{\mathrm{p}}^{2-4} \\
\mathrm{Q}_{\mathrm{p}}^{2} \\
\mathrm{Q}_{\mathrm{p}}\end{array}$ & & & $\begin{array}{l}260 \\
110 \\
350\end{array}$ & $\begin{array}{c}250 \\
95 \\
250\end{array}$ \\
\hline $\begin{array}{l}W_{n_{3}} \\
F_{W_{\mathrm{n}_{3}}}\end{array}$ & $\begin{array}{l}T_{2}-T_{1} \\
T_{3}-T_{2} \\
T_{4}-T_{3}\end{array}$ & $\begin{array}{l}\mathrm{Q}_{\mathrm{p}}^{2-4} \\
\mathrm{Q} \\
\mathrm{Q}\end{array}$ & & & $\begin{array}{l}201 \\
212 \\
248\end{array}$ & $\begin{array}{l}130 \\
171 \\
142\end{array}$ \\
\hline$\frac{J_{3}}{F_{J_{3-1}}}$ & $\begin{array}{l}T_{2}-T_{1} \\
T_{3}-T_{2} \\
T_{4}-T_{3}\end{array}$ & $\begin{array}{l}\mathrm{Q}_{\mathrm{p}}^{2} \\
\mathrm{Q}_{\mathrm{p}}^{2} \\
\mathrm{Q}_{\mathrm{p}}\end{array}$ & & & $\begin{array}{l}290 \\
160 \\
275\end{array}$ & $\begin{array}{l}225 \\
140 \\
270\end{array}$ \\
\hline $\begin{array}{c}J_{3} \\
F_{J_{3-2}}\end{array}$ & $\begin{array}{l}T_{2}-T_{1} \\
T_{3}-T_{2} \\
T_{4}-T_{3}\end{array}$ & $\begin{array}{l}\mathrm{Q}_{p}^{2} \\
\mathrm{Q}_{p}^{2} \\
\mathrm{Q}_{\mathrm{p}}^{1}\end{array}$ & & & $\begin{array}{l}120 \\
140 \\
165\end{array}$ & $\begin{array}{c}78 \\
119 \\
124\end{array}$ \\
\hline $\begin{array}{c}J_{25} \\
F_{J_{25}}\end{array}$ & $\begin{array}{l}T_{3}-T_{2} \\
T_{4}-T_{3}\end{array}$ & $\begin{array}{l}\mathrm{Q}_{\mathrm{p}}^{2} \\
\mathrm{Q}_{\mathrm{p}}^{2}\end{array}$ & & & $\begin{array}{l}243 \\
160\end{array}$ & $\begin{array}{l}220 \\
122\end{array}$ \\
\hline $\begin{array}{l}W_{n_{1}} \\
F_{W_{\mathrm{n}_{1}}}\end{array}$ & $\begin{array}{l}T_{2}-T_{1} \\
T_{3}-T_{2} \\
T_{4}-T_{3}\end{array}$ & $\begin{array}{l}\mathrm{Q}_{\mathrm{p}}^{2-4} \\
\mathrm{Q} \\
\mathrm{Q}\end{array}$ & & & $\begin{array}{l}148 \\
236 \\
189\end{array}$ & $\begin{array}{l}130 \\
200 \\
165\end{array}$ \\
\hline
\end{tabular}

In addition, in the $W_{n_{6}}, J_{29}$ and $J_{24}$ seismic time-depth profiles, the reflected wave group is stable and continuous. The reflected wave groups around stake number 900 in the $W_{n_{6}}$ profile, the reflected wave groups near CDP3235 in the $J_{29}$ profile and the reflected wave groups near CDP1240 in the $J_{24}$ profile have changes, and the changes are mainly caused by the change of the 
observing system. By comprehensive analysis, the above profiles indicate that no fault exists (Figure 9).

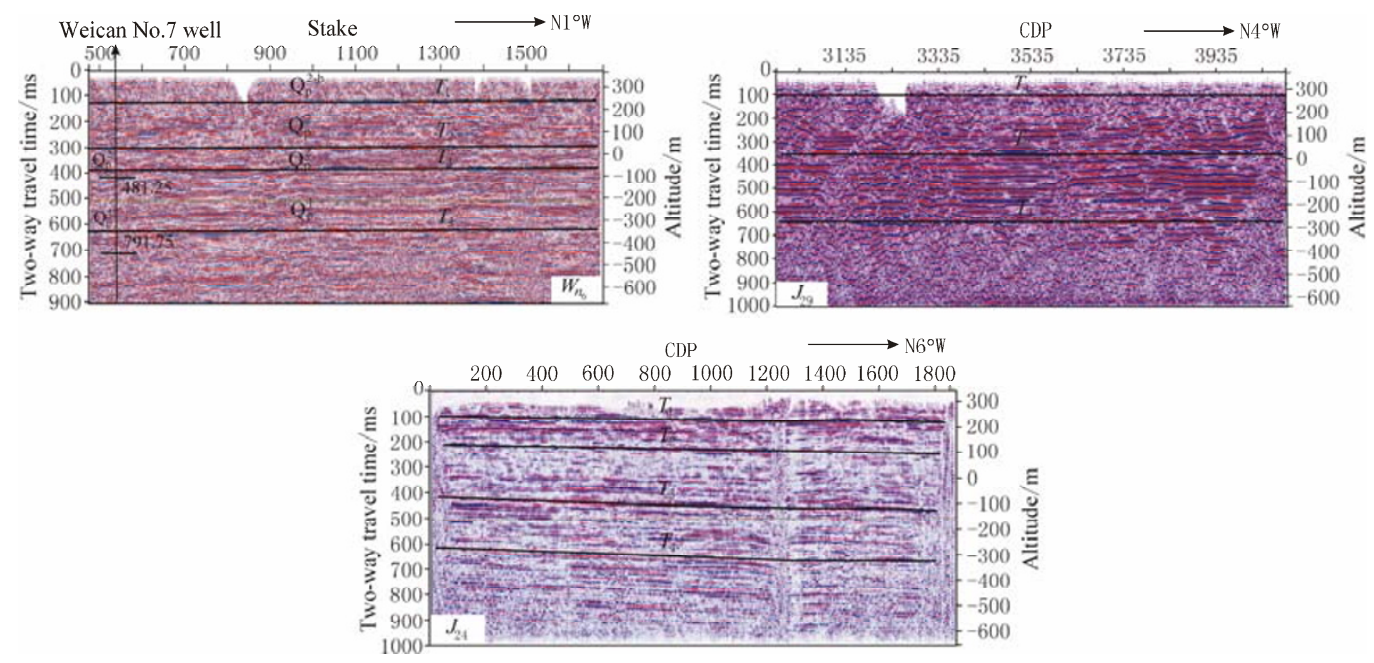

Figure 9 The time-depth profile of seismic reflection with no indication of fault $T_{1}$ : The strong reflecting interface; $\mathrm{Q}$ : The quaternary system; $\mathrm{Q}_{\mathrm{p}}^{2+\mathrm{h}}$ : The mid Pleistocene series to the Holocene;

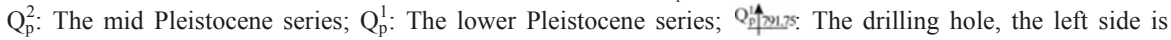
strata, the data on the right side is the depth of the strata on the left side; $J_{24}$ : The seismic survey line number

\section{Distribution of the Weihe Fault}

The exploration results of deep reflection and high-resolution refraction indicate that the depth of the Weihe northern bank fault in the west of Xianyang is about $15 \mathrm{~km}$, the depth of the fault in intersection part of the Weihe river, Jinhe river and the Bahe river on the east is about $6 \mathrm{~km}$, and the depth is gradually shortened from the west to east. According to the shallow seismic detection result, the fault locates on the northern bank of the Weihe river and the west of Jinghe river near the Earth's surface; the fault can extend to $J_{28}$ survey line from the west to east, the survey line $J_{29}$ and $W_{\text {n6 }}$ survey line seismic profile on the east of Jinhe river do not have the display of fault; the fault on the east of Jinghe river should be another fault. The fault on the west of Jinghe river is called the Yaodian-Zhangjiawan fault ( $F_{6-1}$ in Figure 4), the fault starts from Chenjiagou, through Yaodian town, Qianpai village, Bili village, Tongren village, Zhangjiawan to Jiajiatan; the normal trend of the fault is east-west; the fault coincides with the advancing edge of the third stage terrace scarp in Yaodia1n fault; the fault locates at high floodplain in Chenjiagou, Qianpai village, Bili village and Tongren village; the fault locates at low floodplain and riverbed in Zhangjiawan and Jiajiatan. The fault on the east of Jinhe is called Chuanzhang-Zuitou fault ( $F_{6-2}$ in figure 4$)$, the fault starts from Chuanzhang to Zuitou through Mabei and connects with Weinan-Jingyang fault; the trend is near east-west. Two faults above both incline to south.

The exploration results of deep reflection and high-resolution refraction also indicate that the Weihe river southern bank fault does not exist. The seismic profile of each survey line on the southern bank of Weihe river and the east of Bahe river has fault; the fault is tentatively called the Xinzhu-Jiacun fault ( $F_{16}$ in Figure 4$)$. Though the position of the fault is the same as the position of the Weihe southern bank fault, there are two points which can approve that the fault is not the Weihe southern bank fault: (1) the faults incline to south, and it is not in accordance with the opin- 
ion that the Weihe southern bank fault inclines to north. (2) the deep part on the Weihe southern bank and the west of Bahe does not have Weihe southern bank fault, therefore, the Xinzhu-Jiacun fault could not be the east extension of Weihe southern bank fault. The fault possibly is the east extension of new-found $F_{14}$ fault of deep reflection exploration.

\section{Structural characteristic of the Weihe Fault}

From the analysis of the seismic profile, the Weihe fault has the following basic characteristics:

1) The fault is the crystalline basement fault; it is also the upper crust fault. The fault ruptured the reflecting layers of $T_{\mathrm{Q}}, T_{\mathrm{N}}, T_{\mathrm{E}}$ and $T_{\mathrm{g}}$, the depth of the fault is $15 \mathrm{~km}$. The fault inclination angle of the shallow part is steep and becomes gently in deep part, and it is the shovel-shaped normal fault.

2) A secondary fault exists in the deep part of the Weihe fault, for example, the $F_{11}$ and $F_{12}$ fault in the deep reflection profile; the fault and the secondary fault form a Y-shaped fault, or the fault intersects with the secondary fault in a low angle at the same direction.

3) The Weihe fault is one of the faults controlling the basin sediment; it is also the control fault of Xi' an depression and Xianyang salient.

4) The results of controlling shallow seismic detection and detailed shallow seismic detection indicate that in the depth scope of $1000 \mathrm{~m}$, the Weihe fault has the obvious structural characteristics of reversed-drag normal fault and normal traction normal fault, meanwhile, the fault has the characteristic of syndeposition. The fine structural characteristics are different for the fault at different locations.

5) The Weihe fault starts from the position of the deep reflection profile on the west side of Xianyang to the intersection part of the Weihe river, Jinghe river and the Bahe river; the depth changes from $15 \mathrm{~km}$ to $6.0 \mathrm{~km}$ and shortens gradually from west to east; the fault intersects with the Lintong-Chang'an fault in the intersection part of the three rivers, and it connects eastward with the Weinan-Jingyang fault in the shallow part.

\section{Conclusions and problems}

The results of seismic deep reflection, high resolution refraction and shallow seismic exploration show that the Weihe fault from the Yaodian to Zuitou consist of two faults, one is the Yaodian-Zhangjiawan fault and the other is the Chuanzhang-Zuitou fault. The $22 \mathrm{~km}$ long Yaodian-Zhangjiawan fault, striking near EW, starts from Chenjiagou via Yaodian town, Qianpai village, Bili village, Wujia village and Zhangjiawan to the Jiajiatan. The Chuanzhang-Zuitou fault of about $15 \mathrm{~km}$, striking near EW, starts from Chuanzhang via Mabei to Zuitou. The Weihe fault is the basement and upper crust fault which ruptured the reflecting layers of $T_{\mathrm{Q}}, T_{\mathrm{N}}, T_{\mathrm{E}}$, and $T_{\mathrm{g}}$ at the depth of about $15 \mathrm{~km}$. It is a listric normal fault. The Weihe fault is accompanied with secondary faults in deep sections and the main fault and the secondary fault form a Y-shaped structure or a synthetic low angle intersection. The fault within the depth of $1000 \mathrm{~m}$ has the obvious structural characteristics of reversed-drag normal fault and normal drag normal fault, and also has the characteristics of syngenetic sediment. The Weihe fault is not only one of the faults which control the basin sediment, but also the controllability fault of the Xi'an depression and the Xianyang salient. The fault decreases gradually from west to east, the deep part is intersected with the Lintong-Chang'an fault at the intersection of Weihe river, Jinghe river and Bahe river. The lower part 
of the fault is connected with the Weinan-Jingyang fault.

The seismic exploration results show that no fault exists on southern bank of the Weihe River. The Xinzhu-Jiacun fault in the east of the Bahe river is likely the eastern extension of $F_{14}$ fault which is newly found by the deep reflection exploration. The results of high resolution seismic exploration indicate that the fault seemingly exists, but there still need more evidence and further study to support its existence.

\section{References}

FENG Xi-jie, DAI Wang-qiang, DONG Xing-hong. 2003.a Quaternary activity of the Weihe fault obtained from the analysis of Gushui trough profile in Fufeng County, Shaanxi Province [J]. Earthquake Research in China, 19(2): 188-193 (in Chinese).

FENG Xi-jie, TIAN Qin-jian, SHEN Xu-hui. 2003b. Analysis of activity difference of the west section of the Weihe fault [J]. Geological Review, 49(3): 233-238 (in Chinese).

FENG Xi-jie and DAI Wang-qiang. 2004. Lateral migration of fault activity in Weihe basin [J]. Acta Seismologica Sinica, 17(2): 190-199.

FENG Xi-jie, LI Xiao-ni, REN Jun, et al. 2008. Manifestation of Weihe fault at deep, middle-shallow and near-surface depth [J]. Seismology and Geology, 30(1): 264-271 (in Chinese).

FANG Sheng-ming, ZHANG Xian-kang, LIU Bao-jin, et al. 2006. The best combination methods and applied research of seismic prospecting for active faults in urban area [J]. Seismology and Geology, 28(4): 646-653 (in Chinese).

PENG Jian-bing. 1992. Tectonic evolution and seismicity of Weihe fault zone [J]. Seismology and Geology, 14(2): 113-119 (in Chinese).

SHI ya-qin, LI Ji, FENG Xi-jie, et al. 2007. The study of Paleoearthquake on the Weihe fault zone [J]. Seismology and Geology, 29(3): 607-616 (in Chinese).

XIANG Hong-fa. 2003. Some problems in the exploration and research of buried active fault [J]. Seismology and Geology, 25(3): 460-466 (in Chinese).

XUE Xiang-xi, LI Wen-hou, LIU Lin-yu. 2002. The northward shift of Weihe River and the uplift of Qinling Mountains [J]. Journal of Northwest University (Natural Science Edition), 32(5): 451-453 (in Chinese).

City Planning Administration of Xi'an, Xi'an Institute of Survey and Mapping. 1998. Atlas of Engineering Geology of Xi' an City [M]. Xi'an: Xi'an Map Publishing House.

YAN Zhen. 1965. Quaternary big rotatory fault in Weihe valley [J]. Quaternaria Sinica, 4(2): 117-118 (in Chinese). 